\title{
Synthesis and Characterization of Nanoporous NiSi-Si Composite Anode for Lithium-Ion Batteries
}

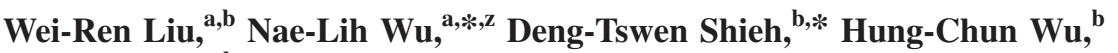 \\ Mo-Hua Yang, ${ }^{\mathrm{b}}$ Christiane Korepp, ${ }^{\mathrm{c}}$ J. O. Besenhard, ${ }^{\mathrm{c}, *}$ and Martin Winter ${ }^{\mathrm{c}, *}$
}

${ }^{a}$ Department of Chemical Engineering, National Taiwan University, Taipei, Taiwan 106

${ }^{b}$ Material and Chemical Research Laboratories, ITRI Chutung, Hsin-Chu, Taiwan 310

${ }^{c}$ Institute for Chemical Technology of Inorganic Materials, Graz University of Technology, A-8010 Graz, Austria

\begin{abstract}
Porous NiSi-Si composite particles having homogeneously distributed intraparticle pores with the size distribution peaked at $200 \mathrm{~nm}$ and a porosity of $\sim 40 \%$ have been synthesized by a novel method, which comprises steps of ballmilling induced reaction to form $\mathrm{Ni} / \mathrm{NiSi} / \mathrm{Si}$ preform particles and subsequent dissolution of unreacted $\mathrm{Ni}$. Upon lithiation/delithiation cycling, the composite particle electrode exhibits much reduced thickness expansion and capacity fading rate, as compared with the pure Si particle electrode. The improvements have been attributed to the success in introducing the preset voids to partially accommodate volume expansion arising from Si lithiation. In situ synchrotron XRD further indicates that NiSi of the composite is active toward Li alloying, and it undergoes reversible transformation to/from $\mathrm{Ni}_{2} \mathrm{Si}$ and $\mathrm{Li}_{y} \mathrm{Si}$. The reversible transformation between the silicides involves volume change in opposite to lithiation of $\mathrm{Si}$, and is beneficial to stabilizing the composite electrode upon charge/ discharge cycling.
\end{abstract}

(C) 2006 The Electrochemical Society. [DOI: 10.1149/1.2402106] All rights reserved.

Manuscript submitted April 24, 2006; revised manuscript received September 18, 2006.

Available electronically December 21, 2006.

Graphite is widely used as an anode material for commercial lithium-ion batteries due to the advantages of low cost, low and flat working voltage, and excellent reversibility. However, the disadvantage is relatively low theoretical capacity, $\sim 370 \mathrm{mAh} / \mathrm{g}$ (or $830 \mathrm{Ah} / \mathrm{L}$ ). The recently announced Sony Nexelion battery adopts tin-based amorphous anode material consisting of multiple elements, such as tin, cobalt, and carbon, which are mixed on a nanometer level. Compared with graphite anode, the lithium ion storage volumetric capacity in Nexelion is increased by $50 \%$, which increases the overall battery capacity by $30 \%$.

Seeking anode materials of even higher capacities, much effort has been carried out and elaborated worldwide on silicon-based material. As an anode material for Li rechargeable batteries, Si has a theoretical capacity greater than $3000 \mathrm{mAh} / \mathrm{g} .{ }^{1}$ However, dramatic volumetric variations, $>300 \%$, upon discharge/charge and poor electronic conductivity hindered its application. A thin-film type of $\mathrm{Si}$ anode, prepared mainly by vacuum sputtering ${ }^{2-5}$ has been demonstrated to exhibit up to 200 cycles at more than $3000 \mathrm{mAh} / \mathrm{g}$, by either tailoring the microstructures of the film and film-substrate interfaces or using films of amorphous Si-containing alloys. Less success has, however, so far been achieved with the conventional thick-film particulate electrode configuration.

One approach to enhancing the cycle life of the Si-based thickfilm electrode is to combine Si with a highly conductive secondary material to form a composite. ${ }^{6-14}$ This secondary material, which can be either electrochemically inactive or active toward $\mathrm{Li}$ alloying, is thought to "buffer" between Si particles for enhancing the stability of the electrode structure during cycling, and concurrently to enhance the overall conductivity of the electrode. The extent of improvement, nevertheless, varies widely, apparently depending heavily on the microstructure and composition of the Si-containing composite.

Previous research had suggested the importance of a porous structure on the dimensional stability of the electrode. The structural design of a loosely packed small particle matrix, for example, was shown to result in significant improvement on cycle stability of a $\mathrm{Sn} / \mathrm{SnSb}$ anode. ${ }^{14}$ In this work, a systematic and viable approach that is capable of introducing homogeneously distributed "preset" voids into the $\mathrm{Si}$ anode matrix is introduced. Specifically, NiSi-Si composite powder was synthesized in a way that it contains a sig-

* Electrochemical Society Active Member.

z E-mail: nlw001@ntu.edu.tw nificant fraction of intraparticle voids with dimensions in the nanometer range and a porosity of $\sim 40 \%$. The electrochemical properties of the composite electrode were characterized by cyclic voltammetry $(\mathrm{CV})$ and charge/discharge (C/D) cycling test, while the electrode expansion effect was also studied by means of electrochemical dilatometry. In addition, the electrochemical Li alloying/ dealloying processes were studied by in situ X-ray diffraction (XRD), and the resolved lithiation mechanism of NiSi turns out to be completely different from what previously suggested. ${ }^{6,7}$

\section{Experimental}

Alloy powders were synthesized by mechanically alloying mixtures of appropriate amounts of high purity elemental powders of $\mathrm{Si}$ (99\%, - 325 mesh, Aldrich) and Ni (5 $\mu \mathrm{m}$, CERAC). The mechanical alloying was performed with a planetary mill (Fritsch Pulverisette P7) under Ar atmosphere using stainless steel vials and balls. The weight ratio of ball:powder is $14: 1$, and $0.5 \mathrm{wt} \%$ of stearic acid $\left[\mathrm{CH}_{3}\left(\mathrm{CH}_{2}\right)_{16} \mathrm{COOH}\right]$ was added as a lubricating agent. After milling at $400 \mathrm{rpm}$ for $16 \mathrm{~h}$, an intermediate phase of $\mathrm{Ni} / \mathrm{Si} / \mathrm{NiSi}$ composite was formed. The resulting powder was put in $0.5 \mathrm{M} \mathrm{HNO}_{3(\mathrm{aq})}$ for $1 \mathrm{~h}$ to etch off Ni. The amount of Ni dissolved in the etching solution was determined by inductively coupled plasma (ICP) spectroscopy (Optima 3000XL). The powder was finally washed and dried in a vacuum oven at $50^{\circ} \mathrm{C}$ for $6 \mathrm{~h}$.

The composite electrode consists of, on a dry basis, $62 \mathrm{wt} \%$ NiSi-Si composite, $30 \mathrm{wt} \%$ conductive additives, and $8 \mathrm{wt} \%$ binder. The binder was a mixture of styrene-butadiene-rubber (SBR; L1571, Asahi Chemicals) and sodium-carboxyl-methyl-cellulose (SCMC; WS-C, Cellogen, DKS International, Inc.) with 1:1 weight ratio. ${ }^{15}$ The conductive additives included graphitic flakes (KS6, $3 \mu \mathrm{m}$, TIMCAL) and nanosized carbon black (Super P, $40 \mathrm{~nm}$, TIMCAL) with a weight ratio of 5:1. The mixed-slurry was coated on $\mathrm{Cu}$-foil with a final film thickness of $\sim 50 \mu \mathrm{m}$. CR2032 coin cells were fabricated from the electrode for electrochemical characterizations. The pure $\mathrm{Si}$ electrode has been prepared the same way. The counter electrode was lithium foil. The electrolyte was $1 \mathrm{M}$ $\mathrm{LiPF}_{6}$ in ethylene carbonate (EC): ethyl methyl carbonate (EMC) $(1: 2 \mathrm{vol} \%)$ from Mitsubishi. In the adopted two-electrode setup, the voltage referred to herein is measured against the $\mathrm{Li}$ counter electrode.

$\mathrm{CV}$ analysis was performed between 0.05 to $3.0 \mathrm{~V}$ at $10 \mathrm{mV} / \mathrm{min}$. The charge/discharge (C/D) tests were carried out with a constant current-constant voltage (CC-CV) mode within the volt- 


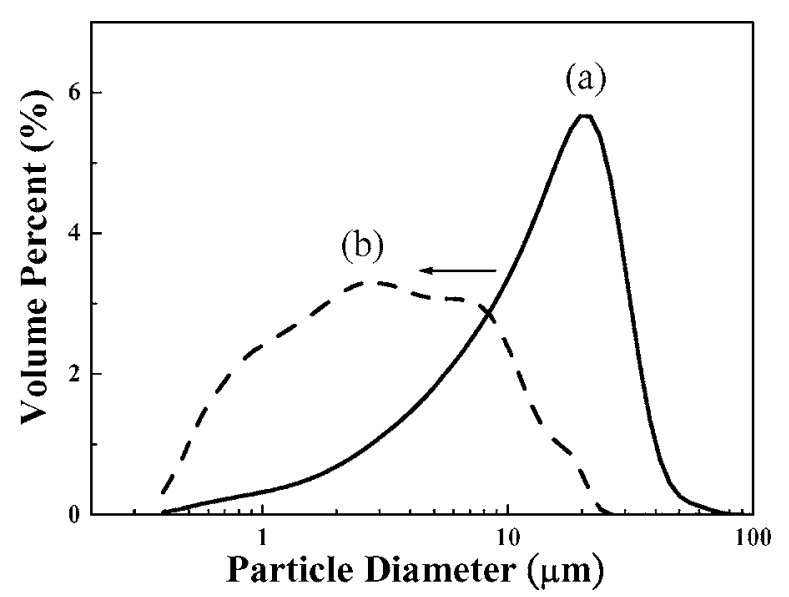

Figure 1. Particle size distributions for (a) as-received Si powder, and (b) NiSi-Si composite.

age range from 0.001 to $1.2 \mathrm{~V}$. The $\mathrm{CC}$ process employed a current of $0.1 \mathrm{~mA} / \mathrm{mg}$, while the $\mathrm{CP}$ process was fixed to $0.001 \mathrm{~V}$ with a cutoff current of $0.03 \mathrm{~mA} / \mathrm{mg}$. The morphologies of the synthesized NiSi-Si material and the fabricated electrodes were examined by scanning electron microscopy (SEM, LEO1530). The preparation of electrode samples for cross-sectional imaging after cycling was carefully carried out in an argon-filled glove box. The cycled electrodes were rinsed by diethyl carbonate (DEC) and dried in a glove box before analysis. XRD was carried out on a MacScience/MXP diffractometer with $\mathrm{Cu} \mathrm{K} \alpha$ radiation. Particle size distribution was determined by light scattering analysis (LS-230, Coulter). The measurements of porosity and pore size distribution were carried out by Mercury porosimetry (AutoPore 9500 IV).

The in situ synchrotron XRD was conducted in the National Synchrotron Radiation Research Center (NSRRC) in Taiwan. The operating energy is $13 \mathrm{keV}(\lambda=0.9537 \AA)$. The measurement of in situ dilatometry was carried out during lithium uptake/extraction to monitor the thickness changes of the electrode. The principle of dilatometric measurement has been described in Ref. 16.

\section{Results and Discussion}

Synthesis and micro-structural characterization.-The asreceived $\mathrm{Si}$ powder has a size distribution that peaks at $\sim 20 \mu \mathrm{m}$ (curve a, Fig. 1) and contains $\sim 77$ vol $\%$ of particles with a size between 10 and $40 \mu \mathrm{m}$. Figure 2 shows the XRD patterns acquired after different periods of milling. Note that the peaks representing

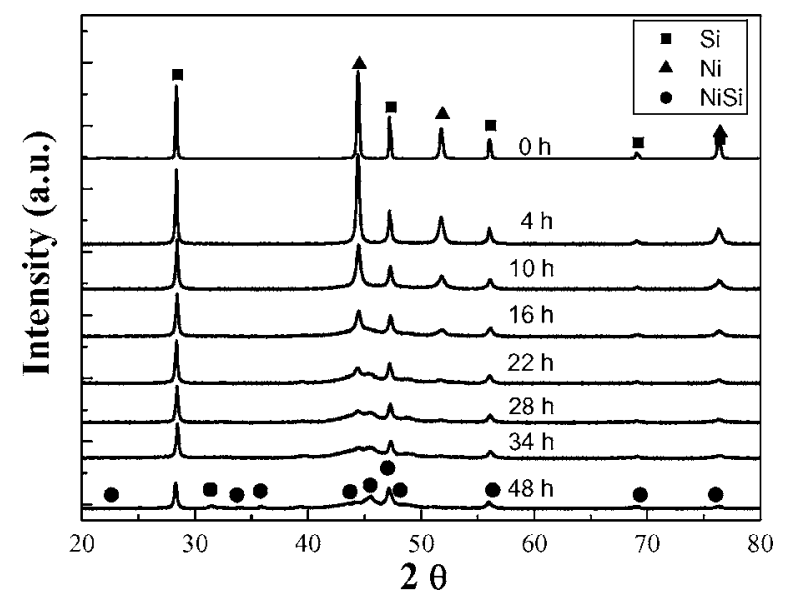

Figure 2. XRD patterns of the milled powder as a function of milling time.

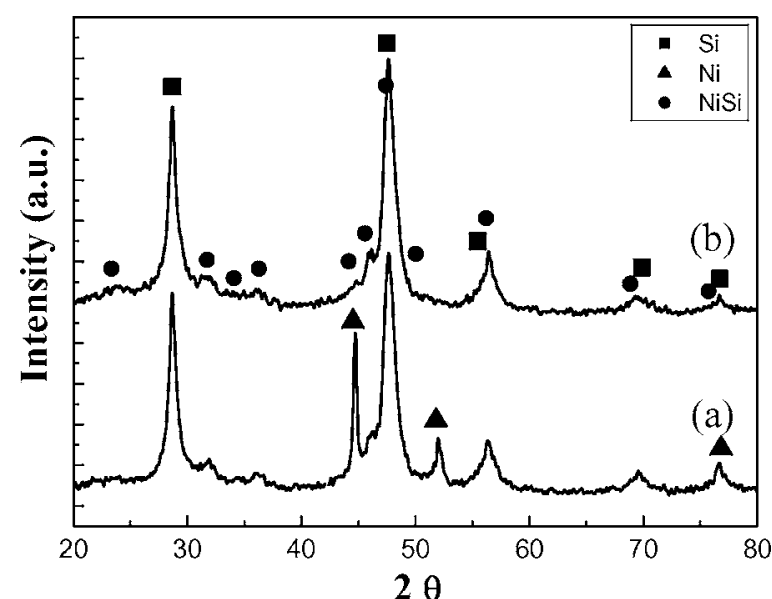

Figure 3. XRD patterns of the porous NiSi-Si composite (a) before and (b) after etching-off of $\mathrm{Ni}$.

the NiSi alloy started to appear after a milling time of $10 \mathrm{~h}$, while the peaks of Ni were no longer detected after a milling time of $48 \mathrm{~h}$ (Fig. 2). Throughout the milling process, NiSi was the sole product detected. Thus, the formation of NiSi by the ballmilling process basically follows a one-step reaction mechanism

$$
\mathrm{Ni}+\mathrm{Si} \rightarrow \mathrm{NiSi}
$$

For preparing the electrode, the powder after $16 \mathrm{~h}$ of milling was etched in diluted $\mathrm{HNO}_{3}$ solution to remove the unreacted $\mathrm{Ni}$. The purpose of the etching step is to increase the overall intraparticle porosity of the composite powder. The XRD patterns of power before and after the etching treatment are shown in Fig. 3. The etch powder was found to consist of only NiSi and Si (line b, Fig. 3). Based on the dissolved amount of $\mathrm{Ni}$, the weight ratio of $\mathrm{NiSi}$ to $\mathrm{Si}$ is determined to be $\sim 76 / 24$ (molar ratio $\sim 1.0 / 1.0$ ). By using the Scherrer's equation, the crystallite size of NiSi was determined to be $\sim 2 \mathrm{~nm}$. The XRD peaks of Si were also found to be considerably broadened after milling, giving an estimated reduction in crystallite size from micrometer size to $\sim 40 \mathrm{~nm}$. Intragrain stress induced by the milling process could also contribute partly to the peak broadening. The particle size distribution of the etched alloy powder showed a broad particle size distribution with $\sim 90$ vol $\%$ of the particles smaller than $<10 \mu \mathrm{m}$ (Fig. 1). SEM analysis showed that the Si particles (Fig. 4a) are nonporous. On the other hand, the composite particles are constituted of numerous submicronmeter particles (Fig. 4b) forming a porous matrix (Fig. 4c). EDX mapping analysis indicates intimate mixing between the $\mathrm{Si}$ and NiSi components (Fig. 4d).

Figure 5 shows the pore size distribution of the NiSi-Si composite. The distribution shows two peaks located at 200 and $600 \mathrm{~nm}$, respectively. The bimodal distribution is typical for a compacted porous powder sample with a large-pore peak $(600 \mathrm{~nm})$ arising mainly from interparticle pores and a small-pore peak $(200 \mathrm{~nm})$ from intraparticle pores. The interparticle porosity forms from compaction. The intra-particle size range is consistent with that shown in the micrograph (Fig. 4c). These two peaks were deconvoluted by assuming Gaussian-type profile, and the total pore volume of the intraparticle pores was determined to be $\sim 0.151 \mathrm{~mL} / \mathrm{g}$. For comparison, the pore distribution of Si powder is also shown in Fig. 5. As the Si particles completely lack intraparticle pores (Fig. 4a), only interparticle pores within the particulate powder exist, and its pore size distribution is indeed located above the range of the intraparticle pores of the composite. Taking into account the theoretical densities of both $\mathrm{Si}$ and $\mathrm{NiSi}$, the composite has a solid volume of $0.238 \mathrm{ml} / \mathrm{g}$, and the porosity is then $38.9 \%$. 


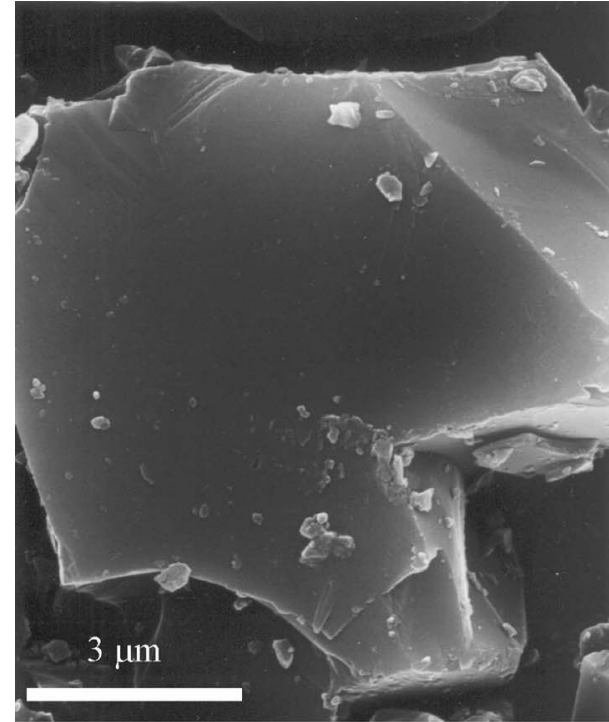

(a)

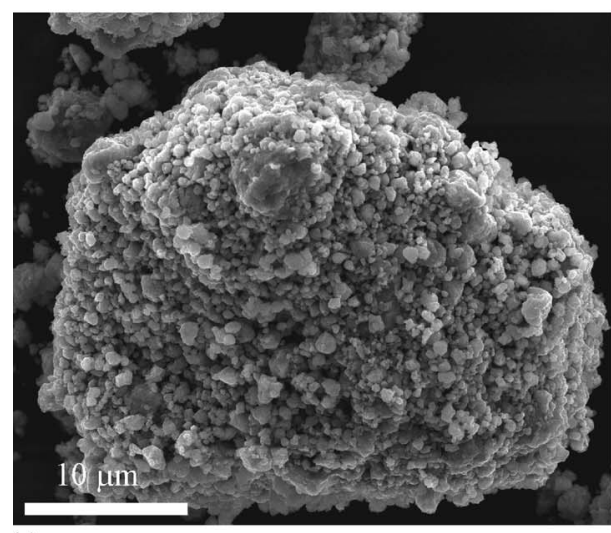

(c)

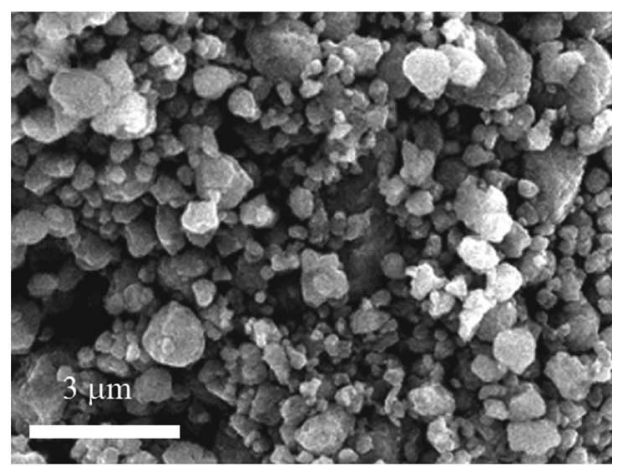

(c)

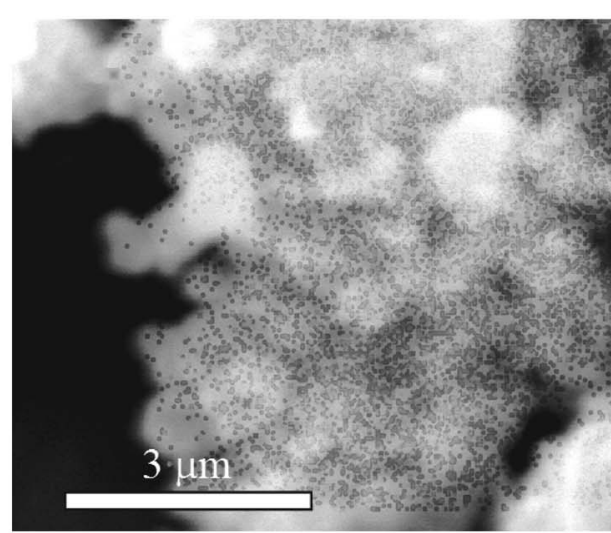

(d)
Figure 4. SEM images of (a) bare silicon, (b) NiSi-Si composite particle, (c) NiSi -Si composite particle at higher magnification, showing the porous nature of the composite particle, and (d) EDS mapping of $\mathrm{Ni}$, where the gray dots indicate the distribution of $\mathrm{Ni}$.
Electrochemical characterization. - The CVs for the first five cycles of the NiSi-Si electrode are shown in Fig. 6a, while those of the fifth cycle for $\mathrm{Si}$ and the composite electrode are compared in Fig. 6b. For the composite, the response current increases with cycle number. A similar phenomenon has also been observed for the pure Si electrode, ${ }^{17}$ and the increase is believed to largely arise from a break-up of particles to provide a larger surface area and thus better

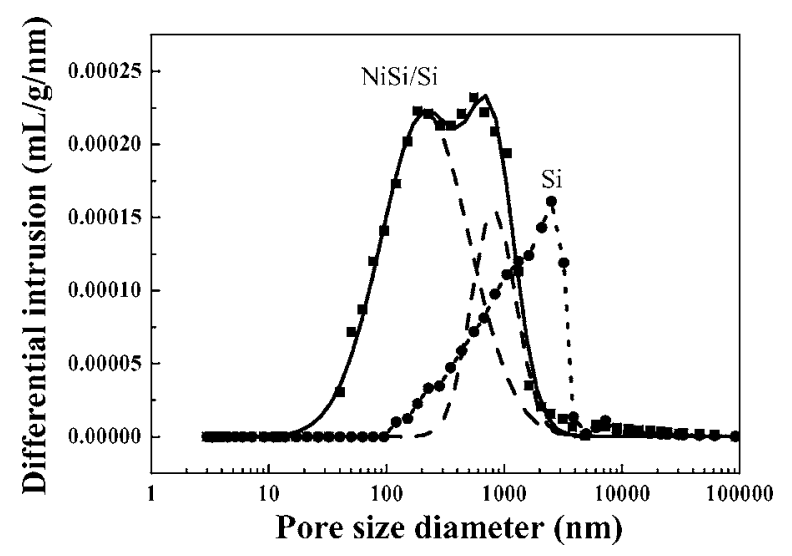

Figure 5. Pore size distributions: (solid-line) NiSi-Si composite powder: (dashed-line) de-convolution of the solid-line by two Gaussian peaks: and (dotted-line) Si powder. kinetics for material utilization. The trace profile, nevertheless, became unchanged after the fifth cycle. For the composite electrode, the reductive (alloying) reaction onsets at $0.8 \mathrm{~V}$ and the current continues to increase exhibiting a peak at $\sim 0.15 \mathrm{~V}$. On the other hand, the Si electrode shows a reductive reaction commencing below $\sim 0.3 \mathrm{~V}$. During the oxidative (dealloying) process, the composite electrode shows a broad hump extending up to $1.0 \mathrm{~V}$, while the $\mathrm{Si}$ electrode shows distinct peaks below $0.6 \mathrm{~V}$. The data indicates that the alloying/dealloying processes of the composite electrode which contains both $\mathrm{NiSi}$ and $\mathrm{Si}$, involves additional redox reactions taking place within higher potential regions to those associated with pure $\mathrm{Si}$.

The cycling capacity data of the $\mathrm{Si}$ and NiSi-Si composite electrodes are displayed in Fig. 7, while the charge/discharge voltage curves of the composite electrode are shown in Fig. 8. For the electrode containing pure $\mathrm{Si}$, the first discharge capacity reached $\sim 3300 \mathrm{mAh} / \mathrm{g}$ (the capacity data referred to herein are based on unit weight of active material, which is either $\mathrm{Si}$ or the NiSi-Si composite), but suffers from $62 \%$ loss upon charge. The dischargeable capacity quickly dropped to $\sim 200 \mathrm{mAh} / \mathrm{g}$ in 5 cycles. At the same current density $\left(0.1 \mathrm{~A} / \mathrm{g}\right.$ or $\left.0.33 \mathrm{~mA} / \mathrm{cm}^{2}\right)$, the $\mathrm{NiSi}-\mathrm{Si}$ composite electrode showed much improved cycling stability. It exhibited an initial discharge capacity of $1250 \mathrm{mAh} / \mathrm{g}$ and $\sim 13 \%$ loss upon charge. The coulombic efficiency quickly reached $>99 \%$ at the second cycle.

Figures 9a-c show SEM images of the cross-section of the Si and composite electrodes before and after cycling. Before cycling, the S and composite electrodes have thicknesses of 55 and $45 \mu \mathrm{m}$, respec- 

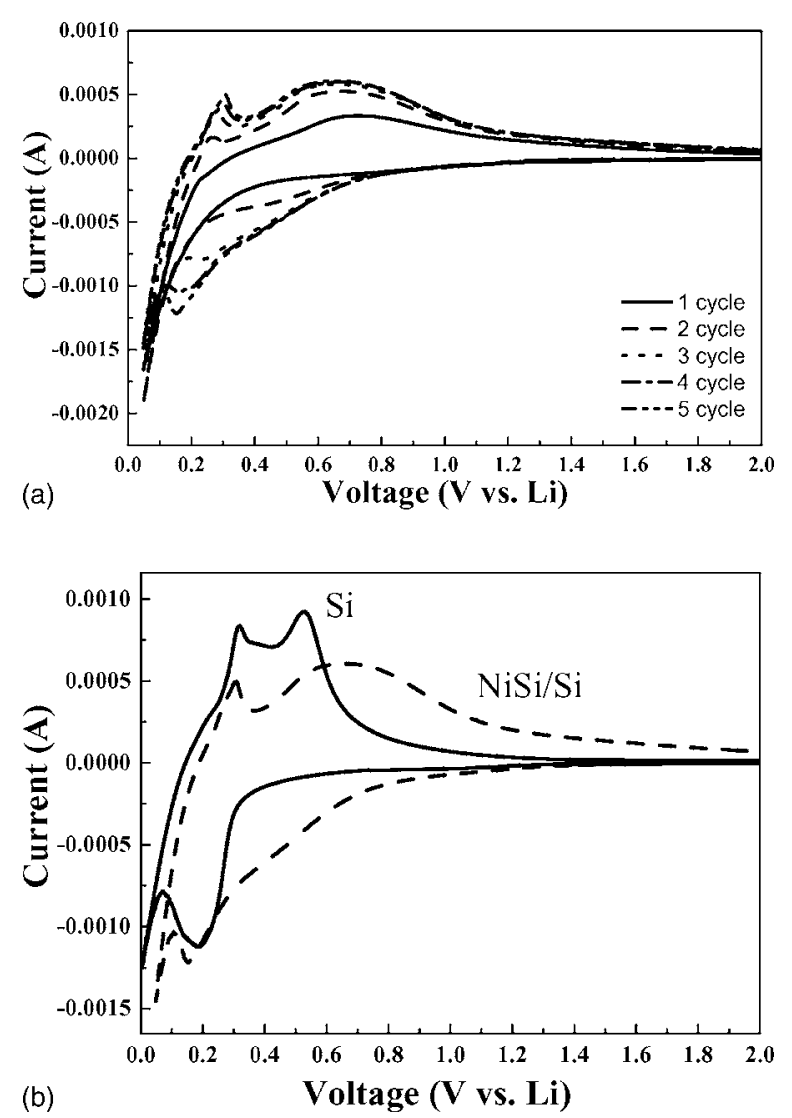

Figure 6. (a) $\mathrm{CV}$ of $\mathrm{NiSi}-\mathrm{Si}$ composite electrode for the first five cycles. (b) Comparison in $\mathrm{CV}$ between pure $\mathrm{Si}$ and $\mathrm{NiSi}-\mathrm{Si}$ composite electrode at the fifth cycle. (Scan rate: $10 \mathrm{mV} / \mathrm{min}$.)

tively (e.g., Fig. 9a for Si). After 10 cycles, the thickness of the pure Si electrode (Fig. 9b) expanded to $200 \mu \mathrm{m}$, while the composite electrode expanded to $96 \mu \mathrm{m}$ (Fig. 9c). In situ dilatometric analysis (Fig. 10) further showed that, for both cases, the electrode expansion took place mainly during the first cycle, and the thickness variations during the subsequent cycles were much milder than that during the first cycle. This may explain, at least in part, why the irreversible capacity loss is most dramatic during the first cycle and died down rapidly upon further cycling, as shown in Fig. 7.

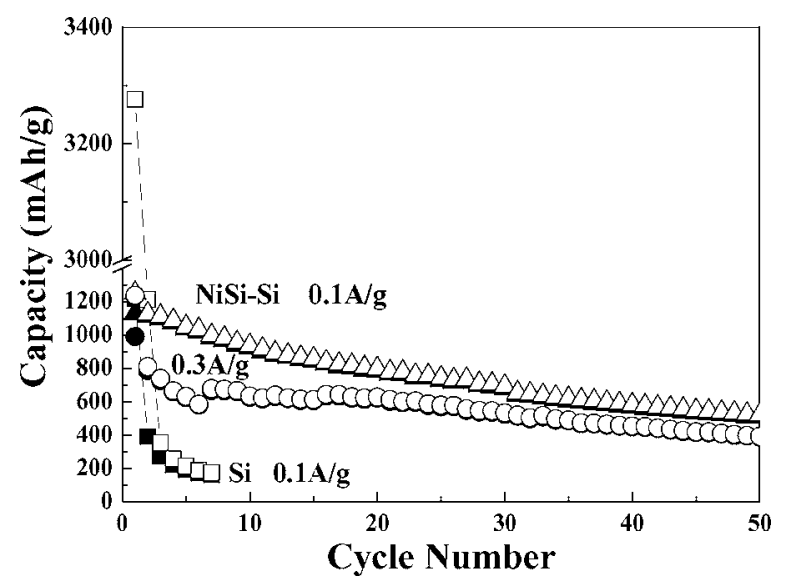

Figure 7. Capacity data of charge/discharge cycling tests of pure $\mathrm{Si}$ and $\mathrm{NiSi}$-Si. The capacity data are based on unit weight of active material, which is either $\mathrm{Si}$ or the NiSi-Si composite. (Open symbols: discharge; solid symbols: charge.)

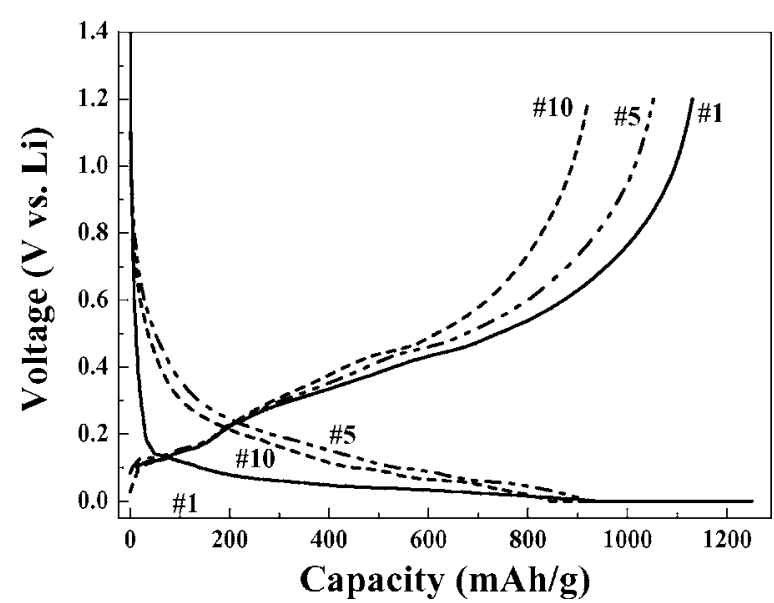

Figure 8. Charge/discharge voltage curves for the NiSi-Si composite electrode at different cycles.

In situ synchrotron XRD study.- The XRD patterns acquired in situ during discharge and charge are shown in Fig. 11a, while the corresponding discharging and charging voltage curves marked with the locations where spectra were acquired are shown in Fig. 11b for reference. As typically occurs during the first discharge, the voltage rapidly dropped to below $0.1 \mathrm{~V}$. Several events were found to occur concurrently then. First, the reflection peaks of graphite [e.g., $\mathrm{C}(004)$ in Fig. 11a] shifted to lower angles, suggesting lattice expansion due to $\mathrm{Li}$ intercalation. Second, the intensities of Si peaks [e.g., $\mathrm{Si}(111)$ in Fig. 11a] decreased with discharge depth, and peaks completely disappear at the depth of $\sim 890 \mathrm{mAh} / \mathrm{g}$. The intensity reduction is apparently due to the alloying with $\mathrm{Li}$ to form amorphous $\mathrm{Li}_{x} \mathrm{Si}$, and the same process has been reported in the literature for the pure $\mathrm{Si}$ electrode. ${ }^{2}$ Third, the intensities of NiSi [e.g., $\mathrm{NiSi}(210)]$ followed the same trend as $\mathrm{Si}$, decreasing gradually with increasing discharge. Finally, a new nickel silicide phase, $\delta-\mathrm{Ni}_{2} \mathrm{Si}$, emerged and its peak intensities increased with increasing discharge.

Upon charge, the events described above were reversed except that the Si peaks remain amorphous and hence undetectable. NiSi reappeared after charging. This is contradictory to the previous suggestion by Wang et al., ${ }^{6,7}$ that the silicide phase irreversibly separated into $\mathrm{Si}$ and $\mathrm{Ni}$ upon the first discharge. No analysis, however, has been given in their study.

Taking into account both the electrochemical characterization and in situ XRD data, the following two sets of alloying reactions are proposed for the NiSi-Si composite system. For the NiSi component

$$
\begin{gathered}
x \mathrm{Li}^{+}+x \mathrm{e}^{-}+\mathrm{NiSi} \leftrightarrows \mathrm{Li}_{x} \mathrm{NiSi} 0.3 \sim 1.0 \mathrm{~V} \\
2 \mathrm{Li}_{x} \mathrm{NiSi}+(y-2 x) \mathrm{Li}^{+}+(y-2 x) \mathrm{e}^{-} \leftrightarrows \mathrm{Li}_{y} \mathrm{Si}+\mathrm{Ni}_{2} \mathrm{Si}<0.3 \mathrm{~V}
\end{gathered}
$$

and for the Si component

$$
y \mathrm{Li}^{+}+y \mathrm{e}^{-}+\mathrm{Si} \leftrightarrows \mathrm{Li}_{y} \mathrm{Si}<0.3 \mathrm{~V}
$$

Equation 2 accounts for the redox reactions taking place within the high voltage region (between 0.3 and $1.0 \mathrm{~V}$ ) as observed in the voltammograms of the composite electrode (Fig. 6). In addition, the XRD data upon discharge (Fig. 11a) showed that the $\mathrm{Ni}_{2} \mathrm{Si}$ peaks were detected only during the very later stage of the diminishing of $\mathrm{NiSi}$ peaks, suggesting that $\mathrm{Ni}_{2} \mathrm{Si}$ may not form in one step from NiSi. Thus, two sequential alloying reaction steps, Eq. 2 and 3, are proposed. The alloyed $\mathrm{Li}_{x} \mathrm{NiSi}$ species is likely to be amorphous, similar to the alloyed $\mathrm{Si}$, and hence no intermediate was detected.

Assuming the $y$ value in Reaction 3 corresponding to $\mathrm{Li}_{15} \mathrm{Si}_{4}^{2}$ gives the theoretical gravimetric capacity of $579 \mathrm{mAh} / \mathrm{g}$ for NiSi and $1298 \mathrm{mAh} / \mathrm{g}$ for the present NiSi-Si composite powder. Taking 


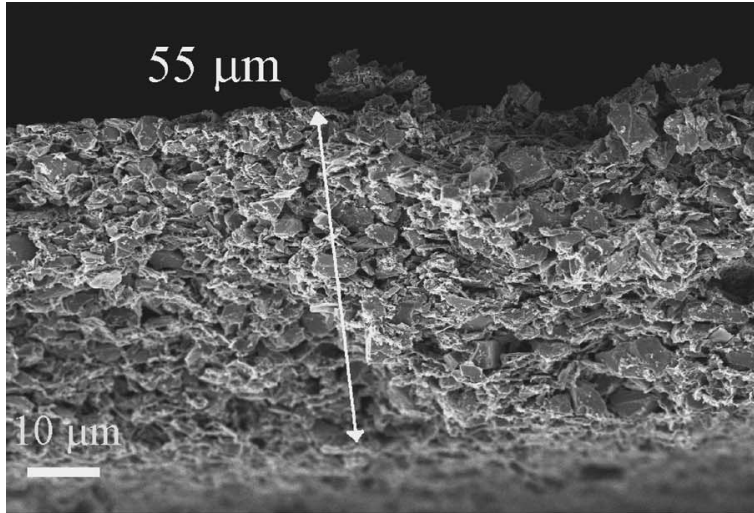

(a)

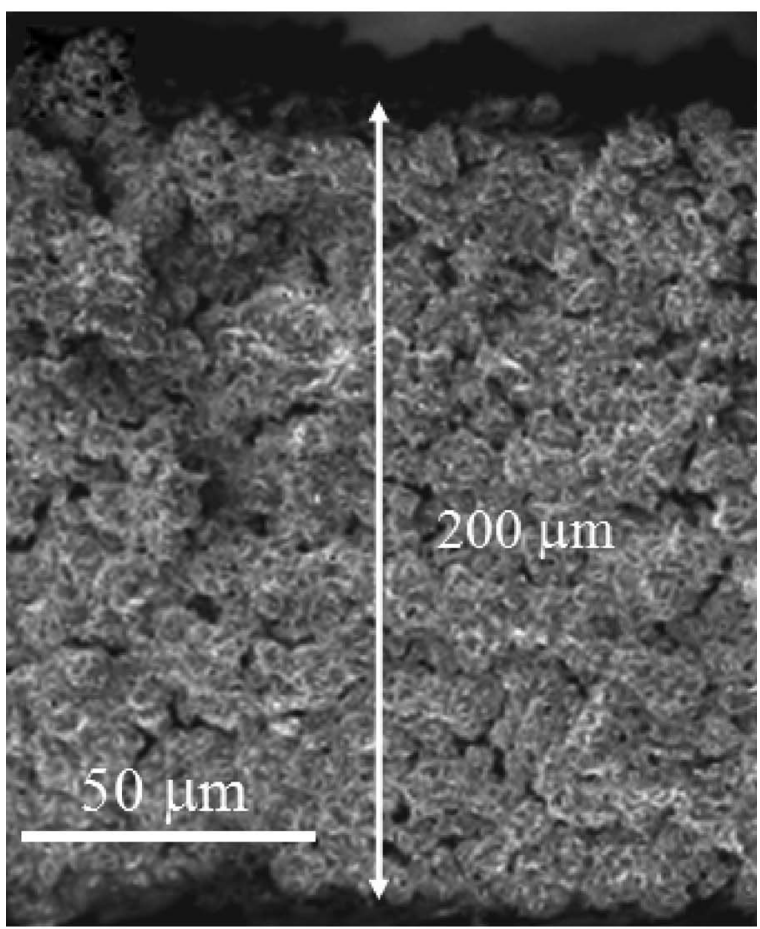

(b)

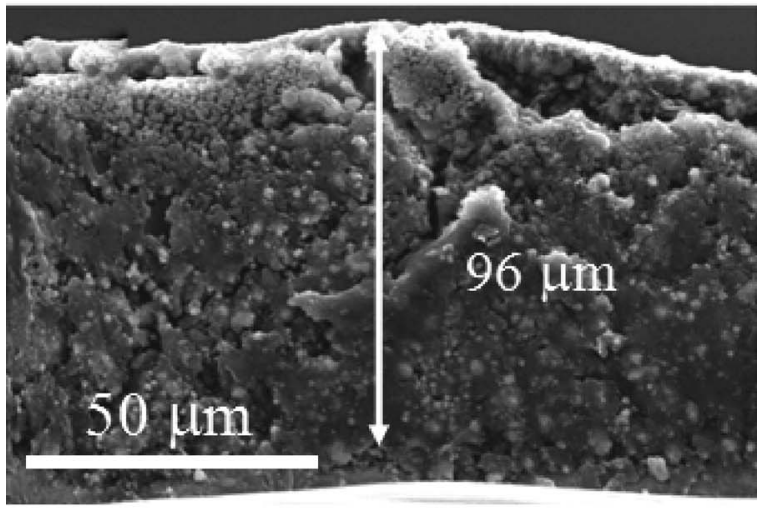

(c)

Figure 9. SEM images of the cross section of electrodes before and after cycling: (a) Si-electrode at fresh state, (b) Si-electrode after 10 cycles, and (c) NiSi-Si electrode after 10 cycles.

into account of the theoretical density, $4.35 \mathrm{~g} / \mathrm{cm}^{3}$, of the composite (molar ratio $\mathrm{NiSi}: \mathrm{Si}=1: 1$ ) gives the volumetric capacity of

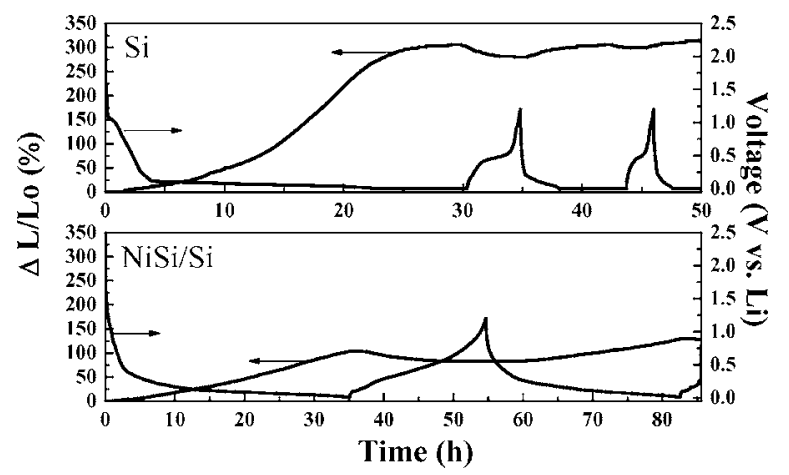

Figure 10. Dilatometric curves of (a) silicon electrode and (b) NiSi-Si composite electrode.

$5646 \mathrm{mAh} / \mathrm{cm}^{3}$ for $100 \%$ dense powder or $3389 \mathrm{mAh} / \mathrm{cm}^{3}$ for the powder with $40 \%$ porosity. For comparison, the gravimetric and volumetric capacities for the graphite are $\sim 370$ and $833 \mathrm{mAh} / \mathrm{cm}^{3}$, respectively. For either gravimetric or volumetric capacity consideration, the present porous powder shows apparent advantage.

Furthermore, the amount of $\mathrm{Si}$ that participates in charging/ discharging in the composite electrode is $2 / 3$ of that in the pure $\mathrm{Si}$ electrode, yet the extent of electrode expansion for the composite electrode is merely $\sim 1 / 3$ that of the pure $\mathrm{Si}$ electrode. The difference indicates that the preset void has indeed served the purpose to
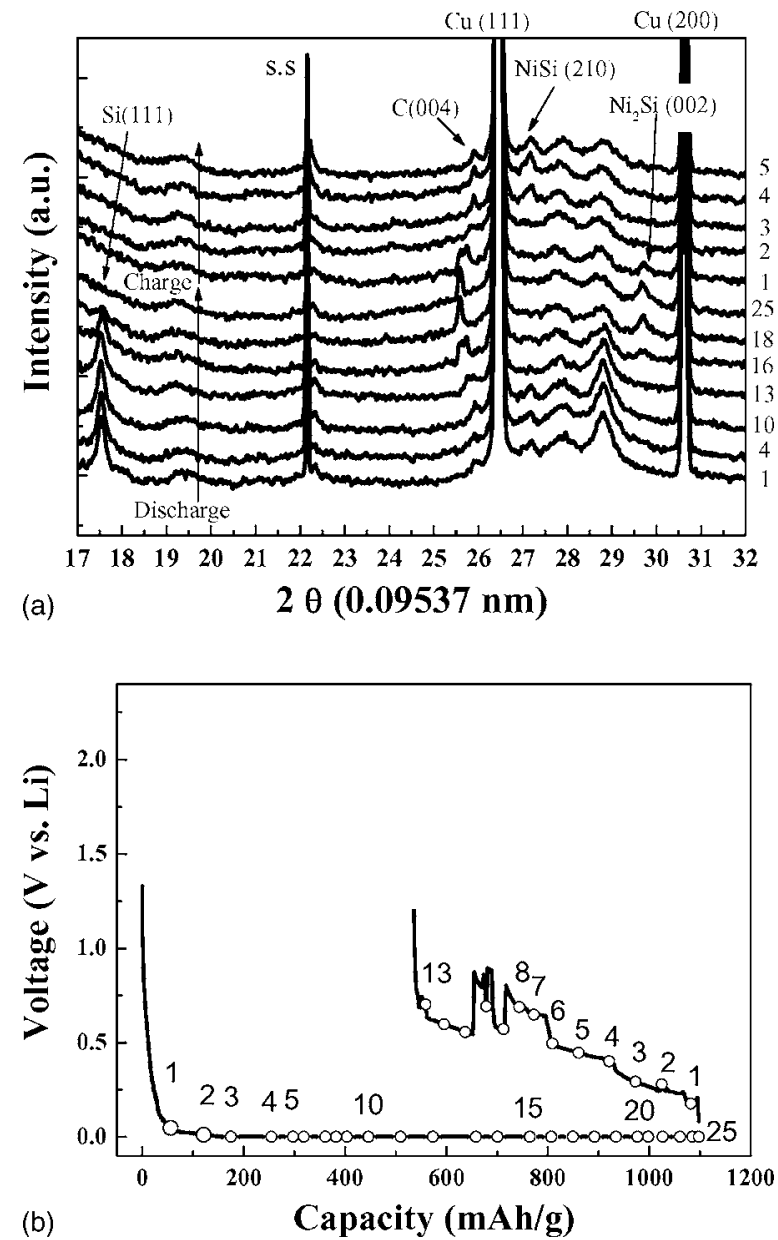

Figure 11. (a) In situ synchrotron XRD patterns of NiSi-Si composite during charge/discharge cycling. (b) The charge/discharge voltage curves are taken during the XRD measurements. The numbers index the XRD patterns. 
partially accommodate the volume expansion arising from the $\mathrm{Si}$ component, and that the reduced thickness expansion in the composite electrode is more than a "dilution" effect, i.e., reduction in $\mathrm{Si}$ content per unit volume. It is also worth mentioning that $\mathrm{Ni}_{2} \mathrm{Si}$ has a density $\left(7.315 \mathrm{~g} / \mathrm{cm}^{3}\right)$ higher than that of $\mathrm{NiSi}\left(5.928 \mathrm{~g} / \mathrm{cm}^{3}\right)$. Thus, the volume shrinkage of the silicide phase could also compensate the volume expansion of the Si component.

Many new anode materials have been proposed in the literature and only a few of them will finally find application after all optimization work has been done. The structural design of our nanoporous $\mathrm{NiSi}$-Si composite in this study has yet to be optimized. The characteristics of final structures, including surface morphology, porosity, and pore size distribution, depend on several synthesis parameters, such as the experimental condition of milling process, etching time, the ratio of $\mathrm{Si} / \mathrm{Ni}$, and so on. It is believed that refinement of these parameters can further improve the cycling stability.

\section{Conclusions}

In this study, porous NiSi-Si particles having a pore size distribution peaked at $200 \mathrm{~nm}$ and an intraparticle porosity of nearly $40 \%$ have been synthesized by high-energy ballmilling of a mixture of $\mathrm{Ni}$ and $\mathrm{Si}$ and subsequent dissolution of unreacted $\mathrm{Ni}$. When used as an anode for Li ion battery application, the preset intraparticle voids have been shown to help to accommodate volume expansion arising from alloying of the Si component. As a result, the composite electrode exhibits much reduced thickness expansion, as compared with pure Si electrode, and hence significantly reduced capacity fading rate upon cycling. Synchrotron XRD further indicates that the NiSi component of the composite undergoes reversible transformation to $\mathrm{Ni}_{2} \mathrm{Si}$ and $\mathrm{Li}_{y} \mathrm{Si}$ during cycling, which is previously not considered mechanism of this material.

\section{Acknowledgment}

This work was supported by Industrial Technology Research Institute and by National Science Council (contract no. NSC94-ET-7002-008-ET) in Taiwan. The authors thank Dr. Hwo-Shuenn Sheu at NSRRC for his assistance on synchrotron XRD analysis.

National Taiwan University assisted in meeting the publication costs of this article.

\section{References}

1. C. J. Wen and R. A. Huggins, Solid State Chem. 37, 271 (1981).

2. M. N. Obrovac and L. Christensen, Electrochem. Solid-State Lett., 7, A93 (2004).

3. H. Yagi and H. Tarui, U.S. Pat. 6,649,033 B2 (2003).

4. L. Y. Beaulieu, T. D. Hatchard, A. Bonakdarpour, M. D. Fleischauer, and J. R. Dahn, J. Electrochem. Soc., 150, A1457 (2003).

5. S. Ohara, J. Suzuki, K. Sekine, and T. Takamura, J. Power Sources, 136, 303 (2004).

6. G. X. Wang, L. Sun, D. H. Bradhurst, S. Zhong, S. X. Dou, and H. K. Liu, J. Alloys Compd., 306, 249 (2000).

7. G. X. Wang, L. Sun, D. H. Bradhurst, S. Zhong, S. X. Dou, and H. K. Liu, J. Power Sources, 88, 278 (2000).

8. J. Hu, H. Li, and X. Huang, Electrochem. Solid-State Lett., 8, A66 (2005).

9. H. Y. Lee and S. M. Lee, J. Power Sources, 112, 649 (2002).

10. M. D. Fleischauer, J. M. Topple, and J. R. Dahn, Electrochem. Solid-State Lett., 8 A66 (2005).

11. J. H. Kim, H. Kim, and H. J. Sohn, Electrochem. Commun., 7, 557 (2005).

12. M. Winter, J. O. Besenhard, J. H. Albering, J. Yang, and M. Wachtler, Prog. Batteries Battery Mater, 17, 208 (1998).

13. J. Yang, M. Wachtler, M. Winter, and J. O. Besenhard, Electrochem. Solid-State Lett., 2, 161 (1999).

14. J. O. Besenhard and M. Winter, J. Power Sources, 68, 87 (1997).

15. W. R. Liu, M. H. Yang, H. C. Wu, S. M. Chiao, and N. L. Wu, Electrochem Solid-State Lett., 8, A100 (2005).

16. M. Winter, G. H. Wrodnigg, Jürgen O. Besenhard, W. Biberacher, and P. Novák, $J$. Electrochem. Soc., 147, 2427 (2000).

17. W. R. Liu, Z. Z. Guo, W. S. Young, D. T. Shieh, H. C. Wu, M. H. Yang, and N. L. $\mathrm{Wu}$, J. Power Sources, 140, 139 (2005). 